\title{
Dynamic Skinfold Thickness Measurements: a Noninvasive Estimate of Neonatal Extracellular Water Content
}

\author{
CYNTHIA J. THORNTON, DONNA L. SHANNON, MARY ANN HUNTER, AND \\ YVES W. BRANS ${ }^{(18)}$ \\ Perinatal Research Laboratory, Departments of Pediatrics and of Obstetrics and Gynecology, \\ University of Texas Health Science Center, San Antonio, Texas, USA
}

\begin{abstract}
Summary
Application of a Harpenden caliper to a neonate's skinfold results in an exponential decline of the skinfold thickness, stabilizing within 50-60 sec. In order to elucidate the meaning of this decline, simultaneous measurements of skinfold thickness (SFT, by Harpenden caliper connected to a chart recorder), corrected bromide space (CBS, in $\mathrm{ml} / \mathrm{kg})$, plasma volume $(\mathrm{ml} / \mathrm{kg}$, by $\mathrm{T}-1824$ dilution) and interstitial water (IW, in $\mathrm{ml} / \mathrm{kg}=\mathrm{CBS}$-plasma volume) were obtained in 18 term and 18 preterm neonates. Skinfold thickness was measured at the midtricipital (MT) and subscapular (SS) sites. The magnitude of SFT decline was estimated as the difference between 0-60 sec readings expressed in $\%$ of 0 second reading $(\% \Delta \mathrm{SFT})$. The rate of SFT decline was estimated as the slope of the semilogarithmic plot from 4-20 sec after caliper application (SASFT).

The 36 neonates whose birthweights ranged from 620-3700 g and whose gestational ages ranged from 27-41 wk were studied

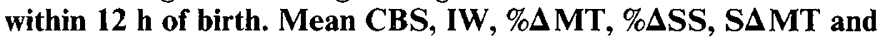
$\mathrm{S} \Delta \mathrm{SS}$ were higher in preterm than in term neonates $(P<0.001)$. Mean plasma volume was higher in preterm neonates $(P=0.009)$, but the difference disappeared after exclusion of six polycythemic term neonates from the calculations. The magnitude of SFT

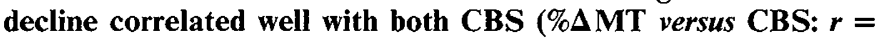
0.71 and $\% \Delta S S$ versus CBS: $r=0.71$ ) and IW (\% $\%$ MT versus IW: $r=0.71$ and $\% \Delta S S$ versus IW: $r=0.70$ ). The rate of decline correlated moderately but highly significantly with both CBS (S $\Delta$ MT versus CBS: $r=0.50$ and $\mathrm{S} \Delta \mathrm{SS}$ versus $\mathrm{CBS}: r=0.42$ ) and IW (SAMT versus IW: $r=0.51$ and S $\Delta$ SS versus IW: $r=$ 0.43). Exclusion of five neonates less than $30 \mathrm{wk}$ in gestation improved the correlations with both $\% \Delta \mathrm{SFT}$ and $\mathrm{S} \Delta \mathrm{SFT}$.

These data suggest that the decline in SFT measurements after caliper application results from the expression of subcutaneous IW from the skinfold and that both the amount of water expressed and the rate of its expression increase linearly with the amount of extracellular and IW in the body.
\end{abstract}

\section{Speculation}

Both the magnitude and the rate of skinfold thickness compressibility or expressibility appear to be intimately related to extracellular and interstitial water contents of the neonatal body. Dynamic skinfold thickness measurements may therefore be noninvasive estimates that are representative of body hydration and that may be used in research on neonatal body composition as well as clinically to evaluate hydration status of sick neonates.

Skinfold thickness measurements are commonly used in anthropometric studies. Our earlier data indicated that in neonates a rapid decrease in measured skinfold thickness occurred after application of a Harpenden caliper, but that readings stabilized by $60 \mathrm{sec}(3)$. We speculated that the difference between the $15-$ and $60-\mathrm{sec}$ readings, expresed in \% of the 15 -sec reading, provided a noninvasive estimate of subcutaneous interstitial water. In order to define the relationship between decrease in skinfold thickness and body water contents, a Harpenden caliper was modified to provide a continuous tracing of skinfold thickness on a chart recorder. Simultaneous skinfold thickness, extracellular and interstitial water estimates were obtained.

\section{MATERIALS AND METHODS}

Thirty-six neonates were studied within $12 \mathrm{~h}$ of birth with their parents' consent. They were selected at random from those neonates who required umbilical vessel catheterization either for aterial blood gas monitoring or for determination of umbilical venous hematocrit to confirm or rule our neonatal polycythemia (10). Birthweights were measured to the nearest $10 \mathrm{~g}$. Gestational ages were calculated from the mother's menstrual history, often but not always checked by sonographic determination of biparietal diameter, and confirmed by physical examination of the neonate (6). A gestation of less than 37 wk defined prematurity. Normal intrauterine growth was defined by a birthweight between the 10th and 90 th percentiles for gestatinal age, sex, and race. Intrauterine growth retardation was defined by a birthweight below the 10th percentile. Separate birthweight-gestational age tables were used for white Latin-American (Gibbs, unpublished data), white Anglo-American (8) and black (8) neonates.

Skinfold thickness was measured at the midtricipital (MT) and subcapsular (SS) sites with a Harpenden caliper (13) as previously described (3). Instead of obtaining measurements exactly 15 and $60 \mathrm{sec}$ after application of the caliper, skinfold thickness was recorded on a chart during at least $60 \mathrm{sec}$ from the time of caliper application. A Harpenden caliper and a Cole Palmer model 837610 linear chart recorder (14) were modified to product continuous recordings of skinfold thickness (Fig. 1 and 2). A linear motion potentiometer was mounted to the right jaw of the caliper while the sliding contact was connected to the left jaw. This contact was adjusted mechanically to the zero point of the linear motion potentiometer. As the jaws were opened, the slider moved across the linear motion potentiometer, causing an increasing voltage to be applied to the recorder input. The voltage was derived from a resistance network connected across a +5 volt source provided by the chart recorder supply and varied proportionally with distance between the jaws of the caliper. The resistor network consisted of a 30 kilo-ohm potentiometer for span adjustment, a 10 kilo-ohm linear motion potentiometer, and a $2 \mathrm{kilo}-\mathrm{ohm}$ potentiometer to counteract nonlinearity of the linear motion potentiometer due to arching of the caliper jaws. A "normally-closed" microswitch, connected in series with the voltage supply, was mounted on the trigger of the caliper. Its function was to break the power connection when pressure was applied to open the jaws of the caliper. 


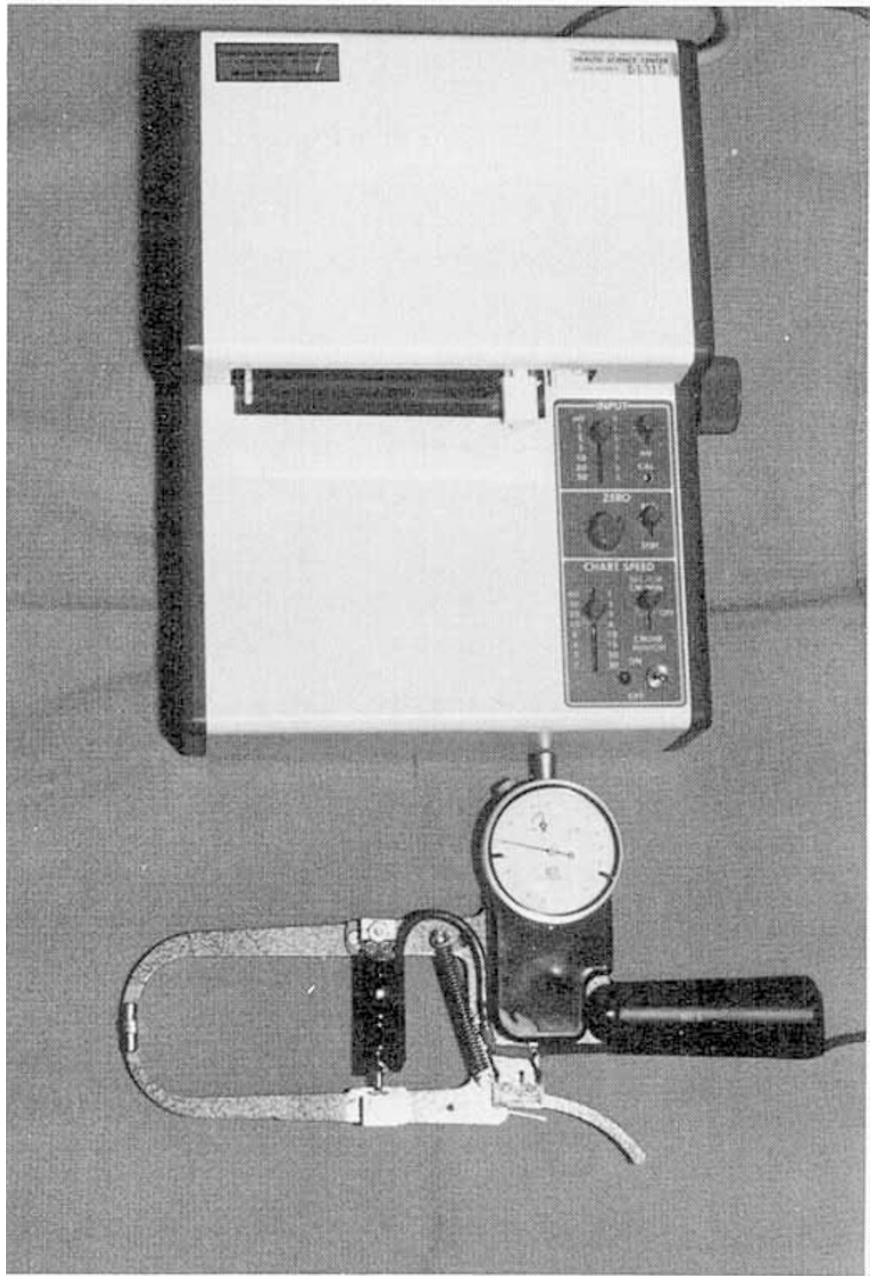

Fig. 1. Modified Harpenden caliper and chart recorder.

This prevented overloading the recorder input when the caliper was opened and allowed a more sensitive setting to be chosen on the recorder. The decline in skinfold thickness with time (Fig. 3) was estimated in magnitude and rate. The magnitude of the decline was estimated as the difference between the 0 - and 60-sec readings expressed as $\%$ of the 0 -sec reading (\% $\Delta \mathrm{MT}$ and $\% \Delta \mathrm{SS}$ ). The rate of decline was estimated by the slope of the decline curve on semilogarithmic plot, from 4-20 sec after caliper application (S $\Delta \mathrm{MT}$ and $\mathrm{S} \Delta \mathrm{SS})$.

Corrected bromide space (extracellular water) and plasma volume (10-min albumin space with T-1824 as the albumin tag) were estimated simultaneously after intra-arterial or intravenous injection via an intravascular catheter of a sterile solution containing $3.9 \mathrm{~g} / \mathrm{dl}$ of bromide (sodium salt) (15) and $22.6 \mathrm{mg} / \mathrm{dl}$ of T -1824 (Evans' Blue) (16) in $0.9 \mathrm{~g} / \mathrm{dl}$ sodium chloride. The exact amount of marker injected was calculated from the measured concentration of the injectate, the weight of injectate administered and the

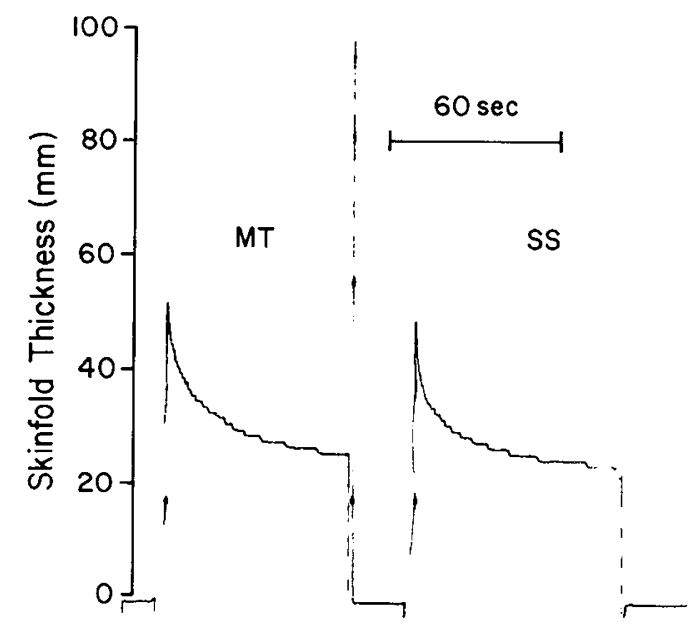

Fig. 3. Typical dynamic skinfold tracings obtained at the midtricipital (MT) and subscapular (SS) sites in a $32 \mathrm{wk}, 1640$ g neonate.

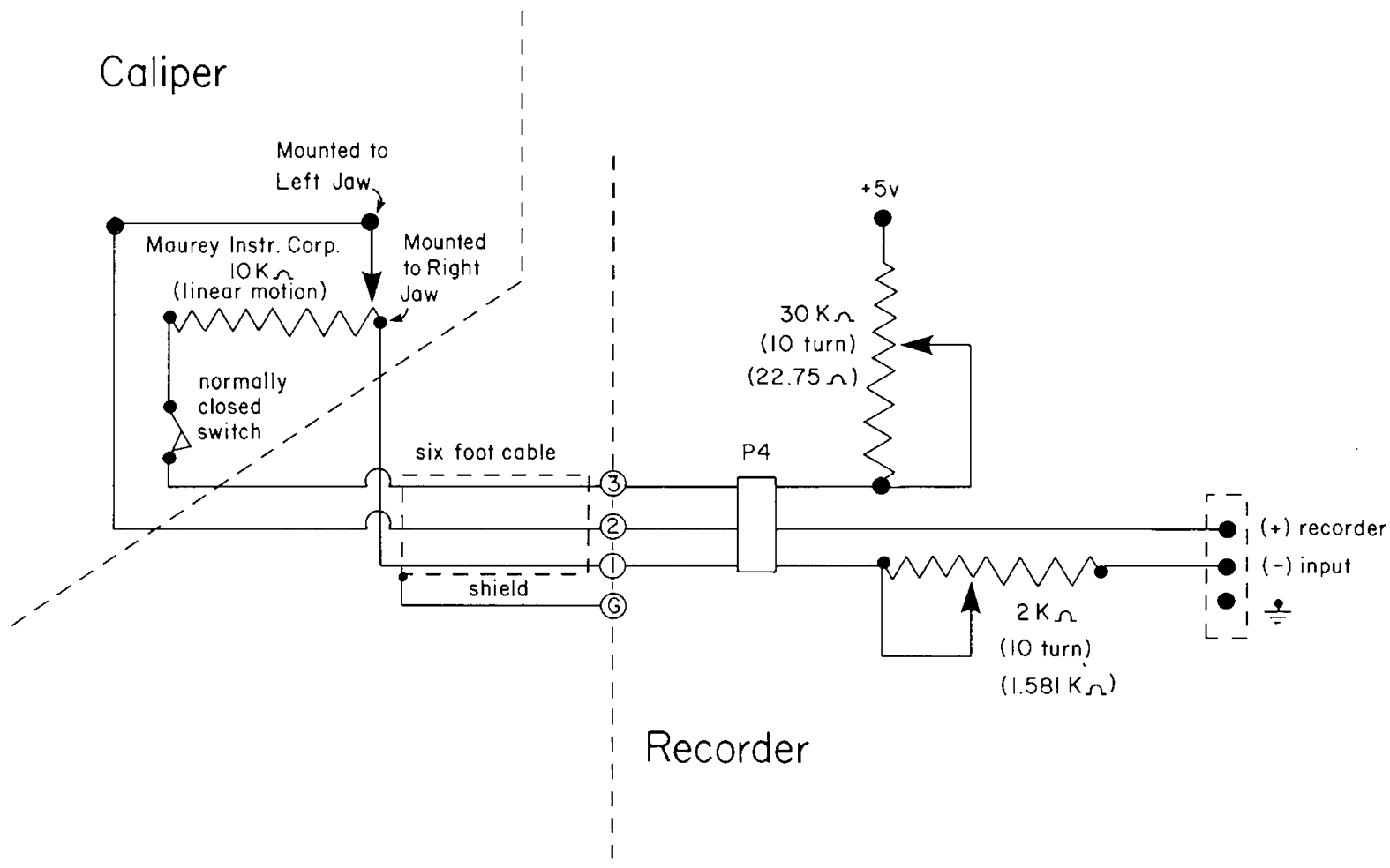

Fig. 2. Schematic drawing of electrical circuitry permitting recording of caliper measurements. 
specific gravity of the injectate. An average of $74.2 \mathrm{mg} / \mathrm{kg}$ (range, $55.5-86.5 \mathrm{mg} / \mathrm{kg}$ ) bromide and $0.5 \mathrm{mg} / \mathrm{kg}$ (range, $0.4-0.6 \mathrm{mg} / \mathrm{kg}$ ) of $\mathrm{T}-1824$ were injected. Bromide concentrations were determined in triplicate on the injectate solution and on plasma samples obtained before and $1 \mathrm{~h}$ after injection of the marker by a microadaptation of Wolf and Eadie's technique (12). The corrected bromide space was calculated using the following formula:

Corrected bromide space

$$
\begin{aligned}
=\frac{\text { Amount of bromide injected }}{1-\mathrm{h} \text { plasma bromide concentration }} & \\
& \times \frac{0.90}{0.95 \times 0.934}
\end{aligned}
$$

where 0.90 corrects for an estimated $10 \%$ intracellular bromide (5), 0.95 corrects for the Donnan equilibrium and 0.934 corrects for the proportion of water in plasma (4). Concentrations of T1824 were determined in triplicate on the injectate solution and on plasma samples obtained before and exactly $10 \mathrm{~min}$ after injection of the marker by a double wavelength technique (2). Interstitial water was assumed to be the difference between corrected bromide space and plasma volume. Volumes were expressed in $\mathrm{ml}$ per $\mathrm{kg}$ of body weight.

Statistical analysis was performed by means of Student's $t$ test and regression analysis.

\section{RESULTS}

Of the 35 neonates who were studied, 23 were boys and 13 were girls (Table 1). All but five were of Latin-American ethnic background, four were white Anglo-American and one was black. Birthweights ranged from $620-3700 \mathrm{~g} ; 19$ neonates were less than $2500 \mathrm{~g}$, six were less than $1500 \mathrm{~g}$ and five were less than $1000 \mathrm{~g}$. Gestational ages ranged from $27-41$ wk; there were 18 term and 18 preterm neonates. Of the preterm babies, five were less than 30 wk. All but one neonate were normally-grown and one term baby was growth retarded in utero. Postnatal age at the time of study ranged from $1.5-11.5 \mathrm{~h} ; 18$ neonates were $6 \mathrm{~h}$ or less, only five were $10 \mathrm{~h}$ old or more.

Results of the variables studied are summarized in Table 2. Mean ( \pm S.D) corrected bromide space (CBS) estimates were significantly higher in preterm than in term neonates $(640 \pm 70.7$ $\mathrm{ml} / \mathrm{kg}$ versus $504 \pm 80.1 \mathrm{ml} / \mathrm{kg}, P<0.001)$. Although mean plasma volumes were higher in preterm than in term neonates $(52$ $\pm 5.8 \mathrm{ml} / \mathrm{kg}$ versus $47 \pm 6.0 \mathrm{ml} / \mathrm{kg}, P=0.009$ ), this difference disappeared when values from six polycythemic term neonates, whose plasma volumes are known to tend to be lower than in their normocythemic peers (2), were excluded from calculations ( $52 \pm$ $5.8 \mathrm{ml} / \mathrm{kg}$ versus $49 \pm 5.8 \mathrm{ml} / \mathrm{kg}$ ). Mean intestitial water (IW) estimates were also higher in preterm neonates $(590 \pm 59.6 \mathrm{ml} / \mathrm{kg}$ versus $457 \pm 79.8 \mathrm{ml} / \mathrm{kg}, P<0.001)$. Decreases in skinfold thickness measurement, estimated both in magnitude and in rate, were on the average greater for preterm neonates. Mean $\% \Delta \mathrm{MT}$ were $35 \pm 8.9 \%$ for preterm and $23 \pm 4.5 \%$ for term neonates $(P$ $<0.001)$ and mean $\% \Delta$ SS were $39 \pm 7.4 \%$ and $23 \pm 6.2 \%$, respectively $(P<0.001)$. Mean $\mathrm{S} \Delta \mathrm{MT} \times 10^{4}$ was $45 \pm 15.3$ for preterm babies and $27 \pm 9.8$ for term neonates $(P<0.001)$,

Table 1. Characteristics of the study population (mean \pm S.D. and range)

\begin{tabular}{ccc}
\hline Characteristic & $\begin{array}{c}\text { Term neonates } \\
(n=18)\end{array}$ & $\begin{array}{c}\text { Preterm neonates } \\
(n=18)\end{array}$ \\
\hline Birthweight (gr) & $3130 \pm 499$ & $1640 \pm 636$ \\
& $(2180-3700)$ & $(620-2640)$ \\
Gestational age (wk) & $39 \pm 1.4$ & $32 \pm 3.0$ \\
& $(37-41)$ & $(27-36)$ \\
Postnatal age (h) & $7.2 \pm 1.95$ & $5.5 \pm 2.87$ \\
& $(4.0-10.6)$ & $(1.5-11.5)$ \\
\hline
\end{tabular}

Table 2. Body water and dynamic skinfold thickness estimates (means \pm S.D. and range)

\begin{tabular}{cccc}
\hline & Term & Preterm & \\
Variable & neonates & neonates & $P^{1}$ \\
\hline Corrected bromide space & $504 \pm 80.1$ & $640 \pm 70.7$ & $<0.001$ \\
$(\mathrm{ml} / \mathrm{kg})$ & $(396-655)$ & $(541-762)$ & \\
Plasma volume & $47 \pm 6.0$ & $52 \pm 5.8$ & $=0.009$ \\
$(\mathrm{ml} / \mathrm{kg})$ & $(37-58)$ & $(44-64)$ & \\
Interstitial water & $457-79.8$ & $590 \pm 59.6$ & $<0.001$ \\
$(\mathrm{ml} / \mathrm{kg})$ & $(354-610)$ & $(497-707)$ & \\
$\% \Delta \mathrm{MT}(\%)$ & $23 \pm 4.5$ & $35 \pm 8.9$ & $<0.001$ \\
$\mathrm{~S} \Delta \mathrm{MT} \times 10^{4}$ & $(15-40)$ & $(17-53)$ & \\
& $27 \pm 9.8$ & $45 \pm 15.3$ & $<0.001$ \\
$\% \Delta \mathrm{SS}(\%)$ & $(13-49)$ & $(19-68)$ & \\
& $23 \pm 6.2$ & $39 \pm 7.4$ & $<0.001$ \\
$\mathrm{~S} \Delta \mathrm{SS} \times 10^{4}$ & $(14-64)$ & $(27-52)$ & \\
& $25 \pm 14.9$ & $46 \pm 13.9$ & $<0.001$ \\
& $(11-70)$ & $(18-71)$ & \\
\hline
\end{tabular}

${ }^{1}$ Term vs Preterm Neonates.

whereas mean $\mathrm{S} \Delta \mathrm{SS} \times 10^{4}$ was, respectively, $46 \pm 13.9$ and $29 \pm$ $14.9(P<0.001)$.

As shown in Figure 4, declines in skinfold thickness measurements correlated linearly with CBS estimates. Excluding skinfold thickness and CBS values from neonates who were less than $30 \mathrm{w}$ of gestation increased the correlation coefficients and decreased the $S_{y \cdot x}$. Although all correlation coefficients were statistically highly significant, the correlation was better for the magnitude of decline, $\% \Delta \mathrm{MT}(r=0.71)$ and $\% \Delta \mathrm{SS}(r=0.71)$ than for the rate of decline, $\mathrm{S} \Delta \mathrm{MT}(r=0.50)$ and $\mathrm{S} \Delta \mathrm{SS}(r=0.42)$.

Declines in skinfold thickness measurements also increased linearly with IW estimates (Fig. 5). Again, the correlations were improved by excluding neonates of less than $30 \mathrm{wk}$ gestation. The magnitude of decline, $\% \Delta \mathrm{MT}(r=0.71)$ and $\% \Delta \mathrm{SS}(r=0.70)$, correlated better with IW than the rate of decline, S $\Delta \mathrm{MT}(r=$ $0.51)$ and $\mathrm{S} \Delta \mathrm{SS}(r=0.43)$.

The various estimates of decline in skinfold thickness measurements correlated well with each other:

$\mathrm{S} \Delta \mathrm{MT} \times 10^{4}=1.23 \% \Delta \mathrm{MT}+0.8$

$$
r=0.72(P<0.001) \mathrm{S}_{\mathrm{y} \cdot \mathrm{x}}=11.2
$$

$\mathrm{S} \Delta \mathrm{SS} \times 10^{4}=1.15 \% \Delta \mathrm{SS}+1.8$

$$
r=0.74(P<0.001) \mathrm{S}_{\mathrm{y} \cdot \mathrm{x}}=11.2
$$

$\% \Delta \mathrm{SS} \quad=0.82 \% \Delta \mathrm{MT}+7.4$

$$
r=0.71(P<0.001) \mathrm{S}_{\mathrm{y} \cdot \mathrm{x}}=7.6
$$

$\mathrm{S} \Delta \mathrm{SS} \times 10^{4}=\left(0.74 \mathrm{~S} \Delta \mathrm{MT} \times 10^{4}\right)+10.8$

$$
r=0.69(P<0.001) \mathrm{S}_{\mathrm{y} \cdot \mathrm{x}}=12.0
$$

\section{DISCUSSION}

Skinfolds contain a double layer of skin and subcutaneous tissues. Their thickness has been commonly equated to that of subcutaneous fat (3). This implies that the double skin thickness is negligible in relation to the total skinfold thickness-an assumption that is certainly not warranted in preterm neonates (Shanklin, personal communication, 1974). Several investigators have noted some decline in skinfold thickness (SFT) readings after application of a Harpenden caliper in children and adults. Fletcher (7) recorded cinematographically a 3-9\% decline over a 2-5-sec period. Booth et al. (1) mentioned waiting for all needle movements to cease before taking a reading. Orpin and Scott (9) observed an initial rapid phase of needle movement and read the SFT when the movement had stopped. No explanation of the decline was attempted by these investigators. In an earlier study, we demonstrated a rapid exponential decline of SFT measurements under 

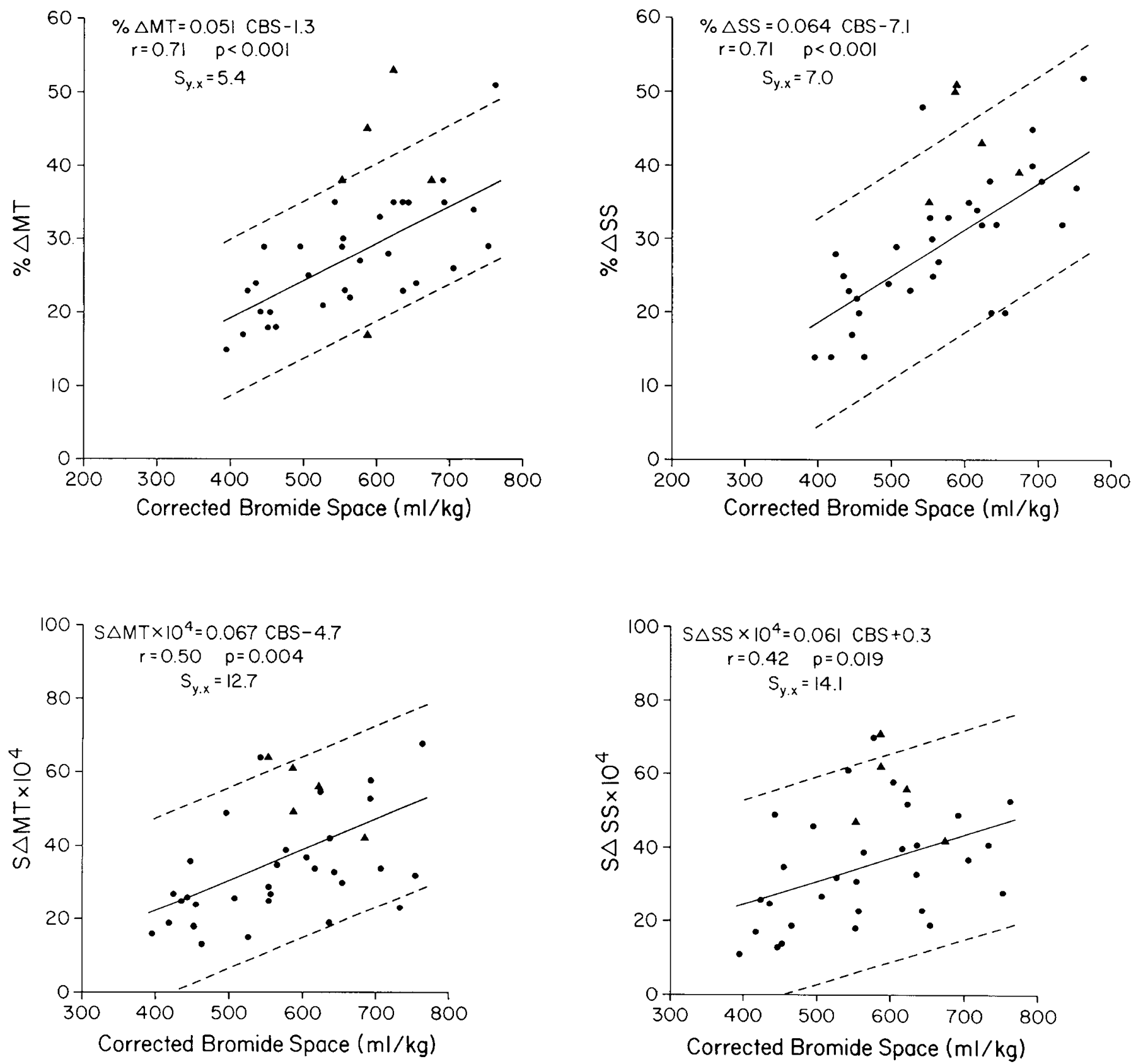

Fig. 4. Relation between decline in skinfold thickness and corrected bromide space (CBS) estimate. Decline in skinfold thickness measured at the midtricipital (MT, left) and subscapular (SS, right) sites are expressed as $\%$ of initial reading $(\% \Delta, t o p)$ and as slope of curve on semilogarithmic plot (S $\Delta$, bottom). The regression line $\pm 2 S_{y \cdot x}$ is superimposed on the scatterplot of individual values. Triangles represent neonates of $27-29$ wk gestation who were excluded from calculations.

caliper pressure in neonates (3). The magnitude of this decline was expressed as the difference between SFT readings obtained 15 and $60 \mathrm{sec}$ after caliper application in \% of the 15 -sec reading (\% $\%$ SFT). The observation that $\% \Delta$ SFT followed a definite pattern related to the degree of gestational maturity and intrauterine growth suggested that the skinfold contained some compressible or expressible component. We postulated this component to be subcutaneous interstitial water. Attempts to correlate $\% \Delta \mathrm{SFT}$ with simultaneously obtained estimates of extracellular water in premature neonates on the one hand, in normally-grown and macrosomic infants of diabetic and nondiabetic mothers on the other hand, failed (unpublished data). Sumners et al. (11), however, reported a weak correlation $(r=0.41)$ between $\% \Delta$ SFT and corrected bromide space, but they defined $\% \Delta \mathrm{SFT}$ as the difference between SFT readings obtained 5 and $60 \mathrm{sec}$ after caliper application expressed in \% of the 5 -sec reading. This report was published in abstract form and never confirmed by a manuscript detailing the data. The inference, though, was that the magnitude of SFT decline during the first $15 \mathrm{sec}$ after caliper application was of key importance.

In order to avoid errors associated with obtaining precisely timed measurements, we modified a Harpenden caliper to produce a continuous recording from the moment of application. Simultaneous estimates of SFT and extracellular water suggest an intimate relationship between the rate and magnitude of SFT decline and both corrected bromide space (or total extracellular water) and interstitial water (or extravascular extracellular water). It does appear, therefore, that the exponential decline of SFT measurements under caliper pressure indeed results from the expression of interstitial water from the skinfold. Because the amount of water expressed increases linearly with the proportion of extracellular water in the body, dynamic skinfold measurement might be useful to assess body hydration noninvasively.

The correlation between both magnitude and rate of SFT 

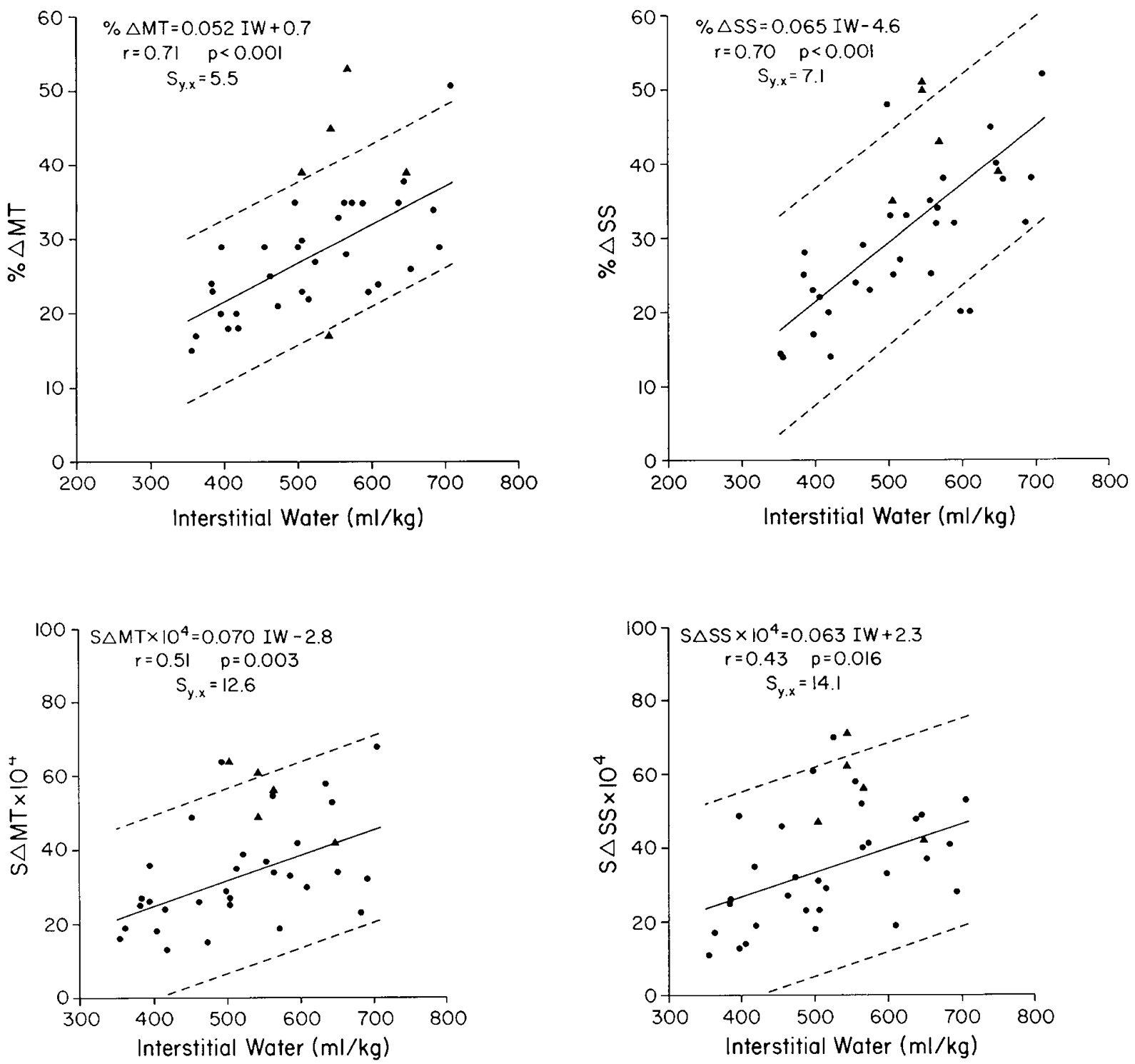

Fig. 5. Relation between decline in skinfold thickness and interstitial water (IW) estimate. Decline in skinfold thickness measured at the midtricipital (MT, left) and subscapular (SS, right) sites are expressed as \% of initial reading (\% $\%$, top) and as slope of curve on semilogarithmic plot (S $\Delta$, bottom). The regression line $\pm 2 S_{y \cdot x}$ is superimposed on the scatterplot of individual values. Triangles represent neonates of $27-29$ wk gestation who were excluded from calculations.

decline with either CBS or IW improved when neonates less than $30 \mathrm{wk}$ of gestation were excluded. This was probably related to the difficulty of securing a large enough skinfold in tiny babies for the caliper to grip and to the possibility that the skinfold contained little or no subcutaneous matter. Calipers with smaller end plates need to be designed for use in less mature neonates.

In conclusion, our data suggest that dynamic skinfold thickness measurements might be indicative of body hydration in neonates and might in some clinical situations replace the more invasive dye-dilution techniques. The magnitude of decline in skinfold thickness $(\% \Delta \mathrm{SFT})$ correlates better with corrected bromide space and interstitial water $(r=0.70-0.71)$ than the rate of decline (S $\Delta$ SFT, $r=0.42-0.51$ ) and would therefore appear to be more useful clinically. With $95 \%$ confidence limits of $\pm 150 \mathrm{ml} / \mathrm{kg}$ for the prediction of corrected bromide space and interstitial water from $\% \Delta$ SFT and $95 \%$ confidence limits of $\pm 200 \mathrm{ml} / \mathrm{kg}$ for the prediction from $\mathrm{S} \Delta \mathrm{SFT}$, the technique is qualitative rather than quantitative. Serial measurements could be expected to be of greater clinical value than single determinations. Further speculation on the clinical significance of the technique must await serial data and data obtained in edematous or dehydrated neonates.

\section{REFERENCES AND NOTES}

1. Booth, R. A. D., Goddard, B. A., and Paton, A.: Measurements of fat thickness in man; a comparison of ultrasound, Harpenden calipers and electrical conductivity. Brit. J. Nutr. 20: 719 (1966).

2. Brans, Y. W., Shannon, D. L., and Ramamurthy, R. S.: Neonatal polycythemia II. Plasma, blood, and red cell volume estimates in relation to hematocrit levels and quality of intrauterine growth. Pediatrics, 68: 175 (1981).

3. Brans, Y. W., Sumners, J. E., Dweck, H. S., and Cassady, G.: A noninvasive approach to body composition in the neonate: dynamic skinfold measurements. Pediatr. Res., 8: 215 (1974).

4. Cassady, G.: Bromide space studies in infants of low birthweight. Pediatr. Res., 4: 20 (1970).

5. Cheek, D. B. and Talbert, J. L.: Extracellular volume (and sodium) and body water in infants. In: D. B. Cheek, Ed., Human Growth: Body Composition, Cell Growth, Energy, and Intelligence. pp 117-134 (Lea and Febiger, Philadelphia, PA, 1968).

6. Dubowitz, L. M. S., Dubowitz, V., and Goldberg, C.: Clinical assessment of gestational age in the newborn infant. J. Pediatr., 77: 1 (1970).

7. Fletcher, R. F.: The measurement of total body fat with skinfold calipers. Clin. Sci., 22: 333 (1962).

8. Freeman, M. G., Graves, W. L., and Thompson, R. I.: Indigent Negro and Caucasian birthweight-gestational age tables. Pediatrics, 46: 9 (I970).

9. Orpin, M. J. and Scott, P. J.: Estimation of total body fat using skinfold caliper measurements. N. Zealand Med. J., 63: 501 (1964).

10. Ramamurthy, R. S. and Brans, Y. W.: Neonatal polycythemia: I. Criteria for diagnosis and treatment. Pediatrics, 68: 168 (1981). 
11. Sumners, J., Burris, S., and Arkans, H.: Compressibility of the skinfold: an index of extracellular volume. Pediatr. Res., 10: 360 (1976).

12. Wolf, R. L. and Eadie, G. S.: Reabsorption of bromide by the kidney. Amer. J. Physiol., 163: 436 (1939).

13. British Indicators Ltd. St. Albans, Hertfordshire, England.

14. Cole Palmer Instrument Company, Chicago, Illinois.

15. Bios Coutelier, Brussels, Belgium.

16. Harvey Laboratories, Philadelphia, Pennsylvania.

17. The authors are grateful to Harry D. Stokes, Frank A. Quijano and Michael F.

Copyright (C) 1982 International Pediatric Research Foundation, Inc. $0031-3998 / 82 / 1612-0989 \$ 02.00 / 0$
McDuffy of the University's Instrumentation Shop for modifying the Harpenden calipers to meet their needs.

18. Requests for reprints should be addressed to: Yves W. Brans, Department of Pediatrics, University of Texas Health Science Center, 7703 Floyd Curl Drive, San Antonio, Texas 78284

19. This research was supported in part by Biomedical Research Grant number RR05654 of the National Institutes of Health, Bethesda, Md.

20. Received for publication December 8,1981 .

21. Accepted for publication June 1, 1982. 